\title{
Learning in occupational transitions: a study of the process following job loss
}

Anders Hallqvist and Lars-Christer Hydén

\section{Linköping University Post Print}

N.B.: When citing this work, cite the original article.

Original Publication:

Anders Hallqvist and Lars-Christer Hydén, Learning in occupational transitions: a study of the process following job loss, 2012, Work: A Journal of Prevention, Assessment and Rehabilitation, (43), 3, 331-343.

http://dx.doi.org/10.3233/WOR-2012-1384

Copyright: IOS Press

http://www.iospress.nl/

Postprint available at: Linköping University Electronic Press

http://urn.kb.se/resolve?urn=urn:nbn:se:liu:diva-76635 


\title{
Learning in occupational transitions - a study of the process following job loss
}

\author{
Authors: Anders Hallqvist and Lars-Christer Hydén, Linköping University
}

\begin{abstract}
Objective: This article examines how workers supported by outplacement services engage with an occupational transition through problem solving and learning. Participants: The participants were 23 mid-life redundant white collar workers with at least eight years in their sector, organization or occupation. The selected interviewees either participated in training to broaden their professional competence or did not make any such 'expansive' efforts. Methods: The study was based on narrative interviews, which enabled a detailed cross case examination of individuals' actions and choices and how the process unfolds over time. Results: The results showed that people treat their job loss as a practical problem to be solved using various strategies. This problemsolving process is structured, with people passing similar crossroads defining particular challenges and opportunities giving people limited sets of choices. Conclusion: The results point to the significance of creativity and learning in occupational transitions.
\end{abstract}

Keywords: job search; outplacement, lifelong learning

\section{Introduction}

Given the significance of work to peoples' wellbeing, job loss and occupational transitions represent major challenges to both individuals and employers. If the job loss occurs in midlife, and if the worker is settled in the occupation, the event could be even more demanding (1). The effects of globalization, the unpredictability of the labour market, high rates of unemployment and the large numbers of redundancies make this area of research a vital one. Moreover, since our notions of career are changing, with lifetime employment being replaced by a necessity for lifelong learning, flexibility and 
work-life mobility (cf. 2, 3, 4), questions about how people manage transitions are becoming increasingly important.

While the negative effects of job loss and unemployment have been widely examined (e.g. 5), what people actually do to deal with a job loss has not. The subject of the present study is therefore the process of transition extending from the notice of redundancy to reemployment. Rather than focusing on the effects of job loss and unemployment, this article examines how people engage with this transition through problem solving and learning.

This study is based on interviews with 23 middle-aged male and female white-collar workers who had been made redundant and were enrolled at an outplacement agency. We chose a qualitative approach using a life-course research design, which enables detailed examination of individuals' actions and choices and how the process unfolds over time.

Like many other white-collar workers in Sweden, their employment security is built on a collective agreement that ensures them outplacement services in times of redundancy. While this specific arrangement is quite unique (6), the use of outplacement services is expanding in European countries to support individuals and to deal with redundancies in a responsible way (7). As will be shown, outplacement services promote both formal and informal learning processes.

The aim of the study is to understand the process through which people engage with an occupational transition. There are many factors that may have an influence on this transition and therefore we delimit the study by specifically look at the process of transition as a sequence of actions and deliberations. Doing this we utilize a view of action present in the tradition of pragmatism $(8,9)$. More specifically, the study addresses the following questions: what pathways are followed, what are the salient crossroads and junctures and how is it possible to understand the choices people make when moving from redundancy to reemployment? 
Drawing on interview data and cross-case analysis of individual trajectories, we suggest that the process of occupational transition, as experienced by white-collar workers participating in outplacement services, leads through several events with adherent choices. The choices people make and the lines of action they follow in the process of problem solving promote learning of different kinds. Also, serendipity is crucial in the process.

\section{Occupational transitions as a problem-solving engagement}

Most research on occupational transitions has focused on young people's transitions between school and work. Today, however, people make several work transitions during their lifetime, some of which are enforced (10). Fouad (10) accordingly states that notions of a career are 'shifting from viewing career as a choice made early in life to viewing career as a series of choices or forced transitions that individuals make over a life span'. However, when research on career development addresses the challenge of transitions, the theoretical perspectives used assume that people make transitions voluntarily and under optimal circumstances (11). Therefore, research needs to address the question of enforced work transitions in adult life under real-life circumstances.

We can identify a number of empirical research traditions related to the present study. One of them has mainly looked for different effects in terms of for instance socioeconomic change, psychosocial and/or health effects following job loss and unemployment (12, e.g. 13). A second tradition approaches the subject from the perspective of the unemployed, studying 'experiences' of job loss and unemployment (e.g. 14). A third tradition focuses on various types of interventions (e.g. outplacement including counselling and psychological assessment) and their effects $(15,16)$. A fourth tradition examines 'job search behaviour', looking at the antecedents and effects of the individual approaches to job seeking (17), methods used to gain information about available jobs and/or contacting employers $(18,19)$, and the significance of social resources (e.g. 20). Though valuable, none of these research traditions looks at the strategies in terms of actions, decisions and professional moves used by people searching for a new job or employment. 
A fifth tradition is research based on the coping concept. This tradition aims at understanding 'the process by which people cope with job loss' (21, p. 311). Research on coping emphasize on the importance of individuals' 'coping goals', arguing that the success of a person's reemployment coping goal predicts the intensity of job searching, which in turn predicts reemployment (22). Others have shown, however, that jobseeking intensity does not mediate the relationship between goal orientation and reemployment outcomes (23). Summarizing their own results from researches on job searching behaviour and pointing out what knowledge is missing, Kanfer et al. made the following comment:

The more difficult issue facing the field pertains to elucidating the person-situation factors, processes, and pathways by which individual differences in job search behaviour affect employment outcomes (24).

It is therefore important to pursue research that aims to describe patterns in individuals' actions dealing with job loss and looking for new employment.

Many researchers assumed that goal-setting and action follow each other linearly in the course of human action: a job loss sets the coping process in motion, pushing the individual to consider his or her situation through a cognitive process called appraisal, which affects the individual's coping goal, which in turn results in coping strategies (cf. 21). One problem with this view is that it does not recognize that people create and recreate goals creatively in the course of the act. Individuals searching for jobs do not have one single, fixed goal; rather they often operate with a variety of different possible 'ends-in-view' $(8,9)$. A further problem with this view is that it does not take into account the role of serendipity in human action.

As an alternative theoretical framework, losing a job and finding a new one can be thought of in pragmatic terms, as problem solving and learning. Through this process individuals change both the situation and themselves, through for instance continued education. Problem solving is often acknowledged as an important coping strategy (25); however, the process of problem solving, its organization and inner structure, is not investigated in coping research. Overall, in narrowly focusing on goal setting and job 
search intensity, previous research does not recognize variation within individuals' coping strategies, creativity and chance. Therefore it is important to look at the actual

actions performed by individuals in their effort to change their situation and the learning that is implied in this process. Actions generally imply various orientations and definitions of a situation, creating a possible space for further action (8). As a consequence it would be fair to assume that these actions over time are sequentially organized and in turn transform and redefine situations, giving rise to new opportunities for future actions.

The suggested theoretical framework has three important implications on learning. Firstly, people learn through action, engagement and problem solving. Secondly, learning is more than adaptation: the actual situation is changed when people act, which is why new opportunities emerge (26). And thirdly, in emphasizing learning and problem solving, it also suggests that agency is 'achieved, rather than possessed' (27).

Unlike previous research, this study addresses on issues of job loss, work transition and learning. The value of integrating these different framework is further supported by the rise and spread of outplacement counselling as a strategy to deal with redundancies and to 'reconcile economic efficiency and social welfare' (7), since outplacement promotes learning in different respects.

\section{Method and material}

The method most commonly used in research on coping mechanisms is surveys, and sometimes longitudinal surveys. If the aim is to study the organization and structure of the process of job transition rather than coping strategies, then survey methodology suffers from at least one limitation: data from surveys are aggregated and only capture momentary properties. Further, surveys tend to approach using a fixed and predetermined set of coping strategies. If, however, career trajectories are rather characterized by discontinuity and inter-individual variability, it is necessary to use a comparative, case-based analysis to capture 'engagement in occupational transitions' (28). 
The project is part of an ongoing cooperation with outplacement agencies focusing on work-life mobility. Through two agencies (TRR Trygghetsrådet and Trygghetsstiftelsen) contact was established with 'mid-life' white-collar men and women, who are participating or had participated in outplacement programmes. In Sweden most whitecollar workers and their employers utilize outplacement services when faced with redundancies. The support offered is individually tailored but generally includes career counselling, courses in job search methods and other educational arrangements that facilitate career decision-making and enhance people's job search abilities. The activities start as soon as a person knows that he or she is going to be made redundant. Sometimes people also receive limited financial support, for example to attend longer courses. When people wish to start a business, they are offered consultation with a business advisor. The employer, too, is offered support and advice on how to conduct the process of redundancy.

We assumed that the learning process would be more pronounced and apparent among people whose participation in outplacement counselling extended for some time, compared to those who quickly found a new work. Further, we assumed that the challenges in connection with work transition would be different for younger people not yet settled in the labour market compared to persons somewhat older and more settled in terms of career, social and economic commitments. People close to retirement age, on the other hand, would tend to be less interested in career change. Hence, we selected individuals between the ages of 35 and 55 years with at least eight years in their sector, organization or occupation and whose participation in outplacement counselling had extended for more than eight months. The selected interviewees either participated in training to broaden their professional competence or did not make any such 'expansive' efforts. In this way we ensured a variation among individuals, covering both ends of a continuum. In total 23 persons were selected (Table 1).

The interview guide was designed to promote narration by encouraging people to talk about the sequence of events, experiences and actions from the notice of redundancy to the present. The aim was to produce data about the course of events and how those events were understood and acted upon. We therefore conducted semi-structured interviews, asking interviewees to tell the story of the transition. The initial interview 
question was: 'I was told that you have been working at (company) but that you lost your job. Would you please tell the story about this and what has happened since then?' To help interviewees remember and develop their narrative, probing questions were asked as well as follow-up questions such as 'And what happened then?', 'What is

Table 1: The interviewees. Names have been changed for confidentiality.

\begin{tabular}{|c|c|c|c|c|c|c|c|}
\hline & $\begin{array}{l}\bar{d} \\
\frac{0}{0} \\
\frac{0}{0}\end{array}$ & 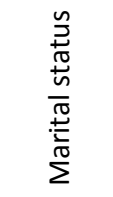 & 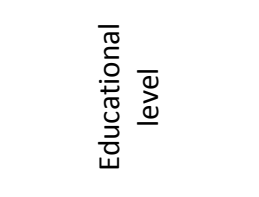 & $\underset{\square}{\stackrel{0}{\alpha}}$ & 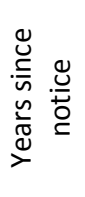 & $\begin{array}{l}\stackrel{0}{\circ} \\
\stackrel{0}{\bar{n}} \\
\stackrel{0}{0}\end{array}$ & 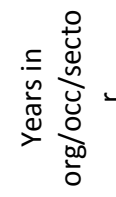 \\
\hline Ann & $f$ & partner & senior high school & 53 & 2 & Business administrator & 25 \\
\hline Britt & $f$ & partner & senior high school & 38 & 5 & Postman & 16 \\
\hline Carl & $\mathrm{m}$ & partner & senior high school & 41 & 2 & Key account manager & 19 \\
\hline Diana & $f$ & single & senior high school & 41 & 2 & Assistant nurse/Industrial worker & $15 / 4$ \\
\hline Erik & $\mathrm{m}$ & partner & $\begin{array}{c}\text { university } \\
\text { (incomplete) }\end{array}$ & 45 & 1 & Key account salesman & 20 \\
\hline Felicia & $f$ & partner & university & 41 & 5 & Engineer & 10 \\
\hline Gabriel & $\mathrm{m}$ & partner & university & 51 & 1.5 & Agricultural manager & 21 \\
\hline Hanna & $f$ & partner & senior high school & 40 & 1.5 & Administrator & 19 \\
\hline Isak & $\mathrm{m}$ & partner & senior high school & 49 & 1.5 & Communication specialist & 20 \\
\hline Jessica & $f$ & partner & senior high school & 39 & 1.5 & Executive official & 9 \\
\hline Katrine & $f$ & partner & senior high school & 50 & 2 & Executive official & 30 \\
\hline Louise & $f$ & partner & senior high school & 45 & 1.5 & Purchaser & 9 \\
\hline Madelene & $f$ & partner & university & 37 & 1 & Sales manager & 12 \\
\hline Niklas & $\mathrm{m}$ & single & $\begin{array}{c}\text { university } \\
\text { (incomplete) }\end{array}$ & 42 & 5 & Postman & 15 \\
\hline Olivia & $f$ & single & $\begin{array}{c}\text { university } \\
\text { (incomplete) }\end{array}$ & 45 & 1.5 & Assistant book-keeper & 10 \\
\hline Paula & $f$ & partner & secondary school & 47 & 3.5 & Restaurant manager & 30 \\
\hline Robert & $\mathrm{m}$ & partner & secondary school & 47 & 2 & Logistician & 10 \\
\hline Sara & $f$ & partner & senior high school & 45 & 4 & Assistant nurse & 23 \\
\hline Therese & $f$ & partner & senior high school & 44 & 1 & Marketing manager & 14 \\
\hline Ulrik & $\mathrm{m}$ & partner & university & 46 & 3 & Engineer & 8 \\
\hline Vendela & $f$ & single & senior high school & 44 & 3 & Receptionist & 10 \\
\hline Ylva & $f$ & partner & senior high school & 42 & 5 & Engineer & 13 \\
\hline Zlatan & $\mathrm{m}$ & single & senior high school & 39 & 2.5 & IT consultant & \\
\hline
\end{tabular}


happening at the present moment?' and 'In five or ten years' time, what will you be doing then?' Interviewees were interviewed once each, with the average length of an interview approximately 70 minutes. The first interview was conducted in March 2008 and the last in January 2009.

The analysis started with careful verbatim transcription of the interviews. The transcriptions were then analysed in four steps. In the first step, salient events that constituted the process of transition in each individual interview were identified, that is, events that were reported and defined as salient by the interviewees themselves. Those events were marked out on a time line. In a second step, actions, situation definitions and orienting efforts in people's trajectories in relation to those events were identified and described. In a third step, the action options were identified, that is, choices that were oriented toward future actions. And in a fourth step all individual cases were analysed through comparative cross-case analysis. Events and actions in the individual cases were compared to identify recurrent event patterns by looking at similarities and differences.

\section{Findings}

Because of the character of the interview guide, we were able to obtain narratives about individual transitions. Examining those narratives, certain events appeared to be crucial to individuals' decision-making since they included options - i.e. they were events with adherent, emergent and salient choices. Thus, the events appeared to be 'choice junctures' that influenced the future course of actions and events. One major finding, therefore, is that the process of orienting from an initial notice of redundancy to looking for educational possibilities, to investing in a new professional career, to looking for a new job, and finally getting one, is not continuous. Rather this process can be viewed as structured into a number of 'choice junctures' characterized by certain challenges, opportunities and outcomes. We identified four such choice junctures with specific challenges, questions to address and decisions to be made. They are described below under the following headings: initial orientation, review and assessment, enhancement 
and relating. As will be shown and subsequently discussed, the choices people make to a large extent concern learning.

Individuals did not necessarily follow one path but decided anew at each point. That is, decisions made at one point open up certain possibilities that lead people in directions they did not necessarily foresee at a previous moment. The problem-solving activities were influenced and aided by the outplacement agency. When participating in individual career counselling and when listening to other people's stories in workshops, people gained support, challenges and stimulation in their career reflections. As a consequence, the activities of the job-seeking individuals were partly structured by the organizational structure and educational arrangements of TRR and TSN.

The participants in this study all enjoyed the benefits of a collective agreement that regulated the process following the redundancy notice. The agreement gave them access to outplacement services including counselling and other educational incentives, and limited financial support. At the same time, however, important differences should be noted, affecting how the individuals initially defined their situation. The period between the first declarations of forthcoming redundancy to the employee's last day at work differed from a few months to more than a year. Other differences include the amount of financial support received during outplacement: some employers offered compensation equivalent to one year's salary; in other cases, the support offered was very limited and came from the outplacement agency. Sometimes financial support was offered to employees taking voluntary redundancy, and in some cases companies supported people who started their own business.

One might presume that all persons received their notice of redundancy in almost the same way and in that sense were able to start from roughly the same situation. In fact, there were noticeable differences in when, where and in what position people received their notice. For instance, people who were active in the trade union and/or with formal or informal relations to senior managers sometimes were aware of the redundancy long before others. Some people were given more or less explicit hints that the company wished to retain them even though they were included in the list of those to be made 
redundant. Given the importance of being prepared, faced with a disruptive event, such differences should not be overlooked.

Further, when receiving notice, people's positions regarding their employment varied significantly. Some people were on parental leave when they received notice of redundancy. Being on parental leave clearly limits an employee's ability to negotiate with his or her employer, similarly his or her opportunities to take part in discussions with colleagues. Since parental leave in Sweden may extend over more than one year, the job loss was perceived at some distance given the relatively long time to reflect. Some of the participants were planning to take courses at university when they received their notice. Of course such a situation also affected the initial response as well as the whole process of outplacement.

Thus, some people were already prepared for the redundancy notice and others were already continuing or were planning to continue their education. Yet others were partially absent from the labour market due to different forms of leave. Though it is predictable that people start the transition from different situations, the point made here is that there were marked differences between individuals in terms of preparedness.

\subsection{Initial orientation: 'Lose and regain' or 'time for a change'?}

Having received a notice of redundancy, there was considerable variation in how difficult and acute people defined their situation. Further, people also varied in how they described their emotional response. Some people characterized themselves as 'cool' (Robert), others as 'depressed' (Eric) or 'sad' (Vendela). Some of the interviewees said that they received the notice with a sense of 'relief' (Diana).

The notice of redundancy also had different meanings for the interviewees. Sometimes this had to do with biographical circumstances, as some interviewees already had an alternative desired work or career path in mind when they received their notice. In such cases the job loss provided these individuals with a chance to make happen something they had been considering, and the redundancy was defined as an opportunity to realize this vision. Others reported that they had problems at work that would have forced them 
to leave anyway - for instance poor working conditions, heavy workload or problematic relations with a manager. In such cases, redundancy was defined as a release: thanks to the redundancy notice, they were liberated from the burden and could now pursue new careers or work possibilities. Yet others stated that they had been treated unfairly in the process, describing their redundancy as an offence.

Focusing not primarily on people's emotional response rather on their engagement in terms of action orientation (although there was a richness and variety here too), it seems possible to make a distinction between two very broad but basic kinds of orientation at this moment: (1) those interviewees that tried to embrace change, and (2) those interviewees that wished to re-establish what they had lost by securing a new job in the same profession or position.

Among the first group, some treated their redundancy as an opportunity to realize a vision. One such person is Ann, a 53-year-old woman who had been working at a large company in a large city for 25 years:

Somewhere in the back of my mind I have always felt I would like to do something completely different (...) and I felt that now perhaps I may get my opportunity to take this leap in life.

To Ann the redundancy was seen as an opportunity to realize a vision. This particular meaning which is assigned to the job loss enables and informs the actions to come. It makes Ann prepared to radically redefine herself, her life, her husband and her children. Her participation in the outplacement services was also influenced by the way she understood the redundancy. Her story reveals that the change is radical and comes about quickly. Immediately after that the company informed her that she would be included in the outplacement programme, she took a holiday and a month later left her home town and the urban milieu to settle in the countryside and set up a youth hostel. Of course, not everyone who embraced change had such a clear vision as Ann. As will be noted later on, some people embraced change without any vision about the future at all.

Other interviewees intended to pursue their existing career. For some of them, the notice of redundancy was accompanied by grief and depression, sometimes anger. Others 
approached the situation in a more controlled way. One of the participants in the study, Vendela, a 44-year-old office worker, represents perhaps what most people regard as a typical occupational transition following involuntary job loss. She became very distressed and wanted to find similar work as quickly as possible:

Your mind was racing at 100 miles an hour: How will I fix this? How? (...) I'm looking for administrative jobs because that is what I can do. I haven't looked for shop assistant jobs, I haven't looked for a job as a rep, well, I know where I like to be, uh I was, I have been working with that since I left senior high school in 1982 and this is my kind of thing

Four weeks after Vendela left her job, she was offered work as a receptionist and, although not ideal, she accepted. Explaining her decision to the interviewer, she stated: 'I can't afford to say no'. To Vendela being unemployed was not a thrilling adventure to realize a vision or an opportunity to enter long-term education, rather a struggle to regain what was lost. It was important to find a new job as soon as possible, and the overall goal was (as she put it) 'to get back to office work'. The result of such an understanding was that Vendela acted enthusiastically and 'conservatively'. Considering herself an administrative kind of person, Vendela looked for a quick solution that meant continuity with her professional history.

Having received a notice of redundancy, people thus considers their situation differently and approaches the future differently. The basic distinction drawn here is between conservative approaches and radical ones: sometimes a redundancy induces change while on other occasions it makes people hold on to their professional identity. At the same time, we should underscore the variation within each group: among those who are open to change some have a clear vision of the future, while others do not, rather they are simply looking for a change. Also when people stick to their current career, they do so with a variety of approaches: sometimes stressed, other times more calmly. These respective orientations of course unfold in different lines of actions influenced, among other things, by the contact with the outplacement agencies. While a 'radical' orientation suggests a thorough exploration of opportunities and intentions, a 'conservative' approach do not call for very extensive efforts in the next step. 


\subsection{Review and assessment: exploration of opportunities and examination of intentions}

When people contacted the outplacement agencies (TRR and TSL), they were offered counselling, workshops and other educational activities. Their competencies, ambitions and need for further education were reviewed; people received guidance on the current labour market situation and on effective job search methods. They were also given information about the alternative of starting their own business and they would receive information from a host of other sources, too, including newspapers, the Internet, and the public employment service. Individual strategies for gaining information varied considerably, as did people's ways of utilizing the outplacement services on offer. Some had only a single phone contact with a counsellor, while others had recurrent meetings and participated in courses and training. Some of the interviewees took up contact with the agency themselves, while others were invited by the counsellor to take part in the services offered.

Partly as a consequence of the institutional interventions, the interviewees at this moment in the process were potentially in a position to systematically review and assess their own situation. For different individuals this meant different things. Some people knew approximately in what direction they wanted to pursue their professional and educational efforts, but hesitated because they needed information of different kinds before making a career decision. They needed to explore what opportunities are at hand. Among those are e.g. entrepreneurs that during the transition tried out different business concepts and developed market plans. Also the group included people who aimed at taking a specific course but needed to know where to find it or they needed to find out how to finance the studies. To others, however, review and assessment did not only include the exploration of opportunities. Those interviewees made a more fundamental review that included an examination of their own intentions. They were rather concerned because they did not know what to do. They questioned their own ambitions, raising issues like what kind of work or occupation they really wanted or whether they perhaps ought to take a course at university. Thus it is possible to draw a distinction between those interviewees who explored (market) opportunities and those who additionally examined their own intentions - before making any career choice. 
One of the interviewees, Gabriel, a 51 years-old agriculture manager, had the intention to becoming a truck-drivers teacher after being made redundant. However, to realize this career change he needed to know more about what the qualifications were, what courses he must take and if he was permitted to apply to those courses at all.

The public employment service and TRR as well... they do not know what opportunities there are. But, I am a rather eager person, and I do not give up, and I am rather good at using the telephone, so I started to call around and check out: what counts if you want to be a truck-drivers teacher? (...) 'What counts really?' (...) and then I spoke to number two (...) and then I begun to realize that using the phone is not enough, one need to start using e-mail: So I sent in one mail after the other (...) and then there was a mail: 'You can apply!'

Gabriel's account is rather extensive; he is talking for a quite a while about all the research efforts that he made before being in position to apply. Thus, when reviewing his situation, far-reaching exploration efforts were necessary to gain information about the proper way forward.

To another interviewee, Felicia, a 41-year-old engineer, review and assess is something rather different. Like Gabriel, she deliberated considerably before making any further career moves; however she did not only explore the opportunities but also her own intentions. Believing that she had chosen the wrong occupation, with redundancy she considered a career change. However, finding a new career proved to be difficult:

I didn't want to return to that kind of work environment any more. What did I want to do? And then we had, at TRR they had one of those 'Have the courage to look for a job' - or whatever they call it - 'course'. And I thought it would build me up, but it was the other way around. I felt I could do nothing (...) I thought it was desperate, really. And what would I do? What would I think? And then I had to act on the basis of what I thought was funny

When reviewing her situation, Felicia put forward questions concerning her own intentions and ambitions and hesitated before making any further choice. She did not know in what direction she should pursue her professional career. She also tried 
different routes before finding the one she wished to follow. Obviously, the activities at the outplacement bureau 'helped' Felicia to think about the situation. The same can be found in other interviewees: people were stimulated to reflect, sometimes radically, about both their former and future work life through the courses and other interventions provided by the outplacement agencies.

To conclude the description of this choice juncture: encouraged by the outplacement agency, people examined their intentions and learned about the labour market situation and available educational options. At this juncture, the choice people make concerns what kind of exploration to utilize. The distinction suggested is between people who explore the market and people who also examine their intentions. Of course there is a third group too, i.e. people who did not review at all but begun applying for jobs right from the start. Any kind of review and assessment was superfluous to them because their career decision was already done.

\subsection{Enhancement: more of the same or engage in extensive learning projects?}

Some of the interviewees found it important to participate in educational activities during the transition to a new job. As has already been pointed out, outplacement is partly an educational arrangement, with most bureaux teaching people about for instance the labour market situation, how to write a $\mathrm{CV}$ and how to perform in job interviews. However, for the present moment, what we have in mind is that people make efforts to enhance not their ability to manage the transition per se but engage in preparations to enhance their professional knowledge, abilities and qualifications.

Both TRR and TSN offered general competence enhancement and supported people's engagement in external educational activities. Some interviewees sensed that they needed to refresh or further develop their current knowledge. Others took long-term courses to change career radically. Yet others needed a certification of some kind to realize their career decision, for instance a driving licence. Most clearly, the need for competence enhancement was evident among would-be entrepreneurs. Thus, people's engagement in preparation varied a lot. Here we will draw a basic distinction between confirmative and enlarging learning projects: while some people attempted to broaden their professional competence, i.e. learn new things, others participated in educational arrangements primarily to confirm and strengthen their current competence. 
Louise, a 45-year-old woman who had been working as a buyer, was one of the interviewees who took a course to verify her existing knowledge:

TRR let me take part in a course in autumn 2007, so that I've got a paper now showing that I'm an assistant bookkeeper (...) I have always had a little econ... uh worked with finance in some way (...) I took 'Office and Distribution' at senior high school. And this, I guess, was a refresher, or how do you say. [I: It was familiar?] Yes, all of it. It was no problem; it was more about getting a piece of paper.

Louise participated in the competence development offered by the outplacement agency. Although she did not really learn much that was new, she regarded the course as a valuable 'refresher' and as a kind of confirmation of her current knowledge. Another interviewee, Therese, applied a different educational strategy. She was 44 and was employed as a marketing manager when she lost her job. Therese found it difficult to find new work and decided to engage in educational activities:

I can speak Danish, but I can't write it. And then I thought, 'but now I can study it!' (...) I was interested in working as a courier or in tourism (...) well, but then perhaps I should take a course in that area (...) Yes, but was there anything else I could think of? And then there was this estate agent thing (...) Now I am studying maths to get the proper [qualifications]

Therese considered the situation as offering an opportunity to enhance her knowledge in different areas of interest to her. She studied Danish and tourism in order to enhance her employability, and she studied maths in case she subsequently changed career to become an estate agent. Clearly, in taking the courses she was expanding her competence in several ways.

The basic distinction at this moment is between on the one hand learning projects that confirm and deepen and on the other hand learning projects that broaden peoples existing professional knowledge. Of course, there is another alternative: sometimes people do not make any learning efforts at all, but rather consider their current competence and qualifications as sufficient. Some refuse to participate in learning 
projects because they do not consider it a positive experience. Motives not to participate in education or training may also be financial: people can lose their unemployment benefit if they enter full-time education. Again there is a crossroads, diverging paths to reemployment; again what route people choose will determine the coming course of events.

\subsection{Connecting to employers and customers: 'non-search', respond or engage in networking?}

The final choice juncture was about what perhaps most - incorrectly as we have seen consider the one and only effort during a transition: choosing the proper job search strategy. The interviewees' engagement took the form of for instance answering advertisements, face-to-face meetings with possible employers or customers, and less formal situations such as a conversation with a manager, colleague, friend or relative.

At the most general level, this moment was about relating to a potential company or employer in order to establish an employer-employee relationship. Among the would-be entrepreneurs, too, this moment in the occupational transition was about relating, not to potential employers but to potential customers in order to establish fruitful customersupplier relationships. To support the clients, the outplacement bureaux offered training in writing applications, how to compile a CV and how to perform in job interviews. In the same way, would-be entrepreneurs were offered consultation on marketing and customer relations.

Among other aspects, the variation turned out to be in intensity or eagerness, as previous research has also shown $(19,29)$. Job search intensity can be measured in terms of frequency or volume ('how often did you apply for a job' or 'how many jobs did you apply for'). Some interviewees did send off many applications, while others did not send off any applications at all but nevertheless gained reemployment or customers without very much effort. Another aspect showing variation was the initiative in the job search process. Some of the interviewees received job offers through the newspaper and sometimes from the outplacement agency. Others called possible employers even though there was no invitation or advertisement to reply to. A third aspect concerned distance 
versus closeness: for some of the interviewees a face-to-face encounter with a potential employer or customer was crucial, and for this reason they visited the other party in person; others by contrast merely sent a letter or e-mail.

Taken together, we identified three different strategies of action. Some of the interviewees were given work opportunities by other people, employers or customers as a result of their existing web of relations, without making any effort themselves. They are sometimes labelled 'non-searchers' (30). The reason may be their strong employability, attractiveness or because they enjoyed the benefits of advantageous social capital. Others were more active and their primary strategy concerned answering advertisements and sending off applications. And finally, some of the interviewees engaged in networking, i.e. made active use of their social network and tried to enlarge it, in order to come into contact with possible employers or customers.

Felicia, mentioned earlier, was an engineer who made a career change to become a teacher after being made redundant. However, later on when she was working as a teacher she decided to start her own business, recruited and empowered by a friend and prospective customer:

I have a friend actually, she works... she she and I talked about jobs a lot, and then she said - I would like to work with you! And uh she has encou encouraged me (...) I had the idea but I haven't really had the courage to put it into practice (...) She said - If you... to get you on board, we have to hire you as a consultant! (...) I have been looking for very few jobs

Felicia said that generally she has not searched for many jobs and this time made no effort at all, rather she was head-hunted by a friend. Although she was successful, such a strategy presupposes trust, high employability and a large amount of social capital.

To Robert, almost the opposite of Felicia, the primary strategy was to answer advertisements: 
There is a lot to apply for really (...) I really [have] a lot of things to do [I: Like?] Well, you have to go through all those staffing agencies, every advertisement uh, it takes a huge amount of time

Robert worked hard to find a job. And his strategy was to read advertisements and reply to them. Consequently, his activity was very dependent on the season, or rather the number of available ads. Though he was active, restricting his activities to replying to advertisement, he did not have the initiative when he was relating to possible employers. Madelene, too, replied to advertisements, but she also used and expanded her social network as a strategy to come into contact with and relate to potential employers:

Next week I will visit an exhibition (...) to meet some people (...) Then, the week after that I will go to Finland to meet (...) my former contacts, meet some people from the food sector in Finland and book a dozen or so meetings (...) And I was at the 'Food Products Day' (...) a month ago, attended by the whole food sector in Sweden (...) I had no company to represent though, I only represented myself. People thought it was a bit strange, but (...) very useful to meet a lot of people and tell them about myself and what I'm good at

Madelene used her professional relationships very strategically. She visited colleagues, conferences and trade fairs, and contacted customers and rival companies as 'you have to keep expanding your network'. Her strategic and agentive approach appeared most clearly when she took part in a conference representing only herself, even though it appeared 'a bit strange' to other conference attendees. Madelene used her professional network, but she also expanded it: she made more and larger nodes in her web of professional relations.

In sum, the question to be addressed at this last choice juncture concerns relating. All engaged in this; however individuals approach the task very differently. The differences partly concern initiative and agency and the way people use and expand their social resources. Three main kinds of engagements were identified: the passive approach where people were given work opportunities through their existing web of relations; an active approach where people responded to job offers found in newspapers or on the 
web; and the networking approach where people actively used and expanded their personal and professional web of relations.

\section{Discussion}

The process through which people deal with job loss is complex and includes several decisions and crossroads. The roads travelled by the interviewees varied, of course, but it appeared equally reasonable to consider them as a process in which people pass similar crossroads and make different choices. While some research strategies presuppose global strategies of action that are assumed to cover the whole process from redundancy to reemployment, the present research has shown that to understand people's engagement we must examine each moment separately. Further, it has shown that learning is a major feature of occupational transitions.

People's initial locations and emotional responses differ significantly; however, the interviewees generally treated their job loss as a practical problem to be solved in some way or another, and they used different actions and strategies at different points in the process to solve or resolve the problem: to get a new job. While previous research emphasizes job-search intensity and its ancestors, the findings of the present study show that job loss may give rise to creativity and learning, and that reemployment is gained not only or not even primarily through goal-setting and intense job seeking.

In this discussion, we wish to address three issues in particular. First the occupational transition process and its various moments. Second, that problem solving and creative action of course imply variation - there are no standard solutions, rather major differences, when the interviewees are compared in detail. Finally, people's pathways are not necessarily linear or straightforward, rather some of the interviewees 'backtrack' to the previous choice junctures.

\subsection{The process and its choice junctures}

Initially we introduced the idea that the process of transition is not continuous but rather structured by several choice junctures. At each moment people encounter different challenges and opportunities. Faced by these, individuals make different choices which 
in turn influence the future course of events. Following a pragmatist's line of thought, the process and structure are basically 'natural' phenomena that occur when people's routine-based action is disrupted - they are thus comparable to other processes of problem solving (cf. 8,9). At the same time, however, the structure here was shaped by the intervention, i.e. the outplacement services. Accordingly, two distinct forces - the 'natural' problem-solving impulse and the institutional arrangements - meet and interact in this process.

\subsection{Variation and underlying patterns}

Variations were found between individuals at each point. But there was also variation within each individual path, since a new decision is made at each moment. Four choice junctures, each with at least two alternatives, means that there will be a large number of different routes. When moving on, the individual faces new choices and people's trajectories diverge several times. Since people make a new choice at each moment, to find out how many different routes there are, one needs to multiply the number of alternatives at each moment together. Thus, the patterns of engagement in occupational transitions are numerous. The large variation among the interviewees indicates that the methods used by the outplacement agencies are not or should not be standardized but 'tailored' and highly individualized. Further, it suggests that the 'natural' process of problem solving is not suppressed but rather released or supported by the intervention. Consequently, occupational transitions embedded in these kinds of outplacement arrangements include creativity and learning. Now, even though the choice junctures are separate and people make new decisions at each moment, there are apparent connections between them, i.e. there are underlying patterns. For example Time for a change is close related to extensive learning projects while Lose and regain is connected to choosing more of the same as educational strategy. The major difference between these two is reflexivity, which is present in the first line of action but less obvious in the second.

\subsection{Going back and forth}

The variation within an individual's trajectory is most obvious when people 'backtrack' to a previous choice juncture in order to make a different choice. Tracking back may occur at different moments and for different reasons. Sometimes people have no success 
when applying for jobs, and for this reason find it necessary to backtrack. Other times people find a new employment opportunity when they are encouraged to start their own business; sometimes people backtrack after competence enhancement, believing that their business concept was not good enough; and sometimes people are offered employment after having just started up their own business. Some people have plural visions concurrently and are thus prepared if the most desirable vision turns out to be a dead end. In such cases, tracking back is managed without a great deal of distress. Those people follow parallel tracks or have an emergency exit built into their career choice.

\section{Conclusions}

\subsection{Learning in transitions}

The main result of this study relates to job loss as an opportunity for novel career choices. Thus, it supports suggestions put forward by Latack and Dozier (31), Eby and Buch (32), Ezzy (33, 34), and Zikic and Klehe (35). However, the study advances our understanding by pointing to the crossroads and choice junctures that are part of the process, arguing that an occupational transition is not continuous. Examining these choice junctures, the study further argues that outplacement services not only provide consolation and information but, perhaps most importantly, promote learning in transitions in several respects. These are outlined below.

Generally and according to the tradition of pragmatism, problem solving brings about new knowledge, and it is for this reason that the whole process leading from redundancy to reemployment should be considered a learning process. Regarding learning outcomes, the transition generates experiences of growth and enrichment, and people's abilities to cope with difficulties in life are improved. Although we do not wish to downplay the negative aspects of job loss and its potential to 'diminish' people and their agency, it is important to highlight that, to people who succeed in moving on to new employment, the process and its outcomes may described in completely different and very positive terms.

Specifically, the considerations and reconsiderations occurring after the second choice juncture mean that individuals learn more about themselves, about the labour market and about the relation between themselves and the labour market. When people reconsider 
their former occupational choice, the transition includes identity work and the remaking of an individual's professional identity. This includes the acquisition of new professional knowledge that occurs after the third choice juncture. Of course, people also learn about the job search process, and how to manage occupational transitions. Finally, people improve their ability to cope with difficulties in life. They thus acquire what might be labelled transitional competence.

Among the several aspects of learning that occur in occupational transitions, the praxis of reflexivity seems to be crucial. Influential theorists $(36,37)$ consider reflexivity to be a major characteristic of late modernity. Further, some educational researchers argue that the 'development of reflexivity' should be central to lifelong learning policies. Looking for a theory of lifelong learning, Edwards, Ranson and Strain (38) argue that there has been little discussion of 'the nature of the learning required to engage with the change processes to which it is meant to be a response' (38). Pursuing this task they propose a 'reflexive' notion of lifelong learning as opposed to an 'adaptive' one: 'it is through self and social questioning (reflexivity) that people are able to engage with and (en)counter be affected by but also affect - contemporary uncertainties' rather than through the 'transmission and acquisition of knowledge and skills' (38). In the same way Alheit (3), when launching the notion of 'biographical learning', points out that identity work is inherent in the learning process that occurs when people cope with change in their life course.

As has been shown above, the practice of reflexivity varies significantly among people who pursue occupational transitions. Some are very attracted by this praxis; others are bothered by it because sometimes questions about life course are thrown up which have no immediate answer. Some people do not seem to consider it as an option, e.g. to question their own current career path. And still others do not initially question their own intentions but indeed do so later on during the process.

\subsection{Emergent agency}

The investigation has shed light on the question of agency in occupational transitions. To find a new orientation, make new career choices and take new actions after being made redundant presupposes 'the ability to exert control over and give direction to one's 
life' (27). The variation among individuals when engaging in the different lines of action indicates that agency is not equally distributed but is 'bounded' by their past and present sociocultural conditions (26). However, the variation within individuals' trajectories indicates that agency may emerge over time, dependent on for instance people's reflective efforts and biographical learning (cf. 27). Focusing on what individuals do when moving from redundancy to reemployment, the present investigation has shown that people's sense of agency emerges in and through a process of problem solving and learning. However, viewing this in relation to intervention, i.e. the outplacement services, it has also been shown that agency is supported when the 'natural' process of problem solving is stimulated through and embedded in institutional arrangements.

\subsection{Serendipity}

If coping with job loss includes learning and agency, it also includes chance and the ability to seize opportunities. Sometimes serendipitous events seem to govern people's careers. In those instances people suddenly find themselves a training course, a job or some other career option. Such opportunistic career choices are not necessarily related to the previous considerations and they may occur at any moment in the process. An opportunity appears; people recognize it as such or as a moment that comprises an opportunity (kairos), and they seize it. To some people, as stated earlier, the redundancy is such a serendipitous event. Others find an opportunity later on. One of the interviewees was offered a job at the end of the process, when she had just started her own business. Sometimes seizing an opportunity is followed by competence enhancement, while on other occasions it is followed by application or immediate reemployment. 


\section{References}

1. Theodossiou I (1998) The effects of low-pay and unemployment on psychological well-being: a logistic regression approach. Journal of Health Economics 17(1), 85104.

2. Garsten C, Jacobsson K, eds. (2004) Learning to be Employable: New Agendas on Work, Responsibility and Learning in a Globalizing World. Palgrave Macmillan, Basingstoke.

3. Alheit P (1995) Biographical learning. Theoretical outline, challenges and contradictions of a new approach in adult education. In The biographical approach in European adult education, Alheit P, Bron-Wojciechowska A, Brugger E, Dominicé P, eds. Verband Wiener Volksbildung, Vienna, p. 57-74.

4. Beck U, Beck-Gernsheim E (2002) Individualization: institutionalized individualism and its social and political consequences, Sage, London.

5. Kieselbach T, Winefield AH, Boyd C, Anderson S, eds. (2006) Unemployment and health: international and interdisciplinary perspectives. Australian Academic Press, Bowen Hills.

6. Sebardt G (2006) Redundancy and the Swedish model in an international context, Kluwer Law International, Alphen aan den Rijn.

7. Kieselbach T, Bagnara S, Witte HD, Lemkow L, Schaufeli W, eds. (2009) Coping with Occupational Transitions. An Empirical Study with Employees Facing Job Loss in Five European Countries. VS Verlag, Wiesbaden.

8. Joas H (1996) The Creativity of Action, University of Chicago Press, Chicago.

9. Dewey J (1916) Democracy and education: an introduction to the philosophy of education,New York.

10. Fouad NA (2007) Work and Vocational Psychology: Theory, Research, and Applications. Annu Rev Psychol 58543-64.

11. Fouad NA, Bynner J (2008) Work transitions. American Psychologist 63(4), 24151.

12. Hanisch KA (1999) Job loss and unemployment research from 1994 to 1998: A review and recommendations for research and intervention. Journal of Vocational Behavior 55(2), 188-220. 
13. Andersen SH (2009) Unemployment and Subjective Well-Being: A Question of Class? Work and Occupations 36(1), 3-25.

14. Vickers MH, Parris MA (2007) "Your Job No Longer Exists!": From Experiences of Alienation to Expectations of Resilience - A Phenomenological Study.

Employee Responsibilities and Rights Journal 19(2), 113-25.

15. Westaby JD (2004) The impact of outplacement programs on reemployment criteria: a longitudinal study of displaced managers and executives. Journal of Employment Counseling 41(1), 19-28.

16. Borgen WA, Maglio AST (2007) Putting action back into action planning: experiences of career clients. Journal of Employment Counseling 44(4), 173-84.

17. McFadyen RG, Thomas JP (1997) Economic and psychological models of job search behavior of the unemployed. Human Relations 50(12), 1461-84.

18. Lambert TA, Eby LT, Reeves MP (2006) Predictors of networking intensity and network quality among white-collar job seekers. Journal of Career Development 32(4), 351-65.

19. Wanberg CR, Kanfer R, Banas JT (2000) Predictors and outcomes of networking intensity among unemployed job seekers. J Appl Psychol 85(4), 491-503.

20. Brown DW, Konrad AM (2001) Job-seeking in a turbulent economy: Social networks and the importance of cross-industry ties to an industry change. Human Relations 54(8), 1015-44.

21. Latack JC, Kinicki AJ, Prussia GE (1995) An Integrative Process Model of Coping with Job Loss. Academy of Management Review 20(2), 311-42.

22. Prussia GE, Fugate M, Kinicki AJ (2001) Explication of the coping goal construct: Implications for coping and reemployment. J Appl Psychol 86(6), 1179-90.

23. Creed PA, King V, Hood M, McKenzie R (2009) Goal Orientation, SelfRegulation Strategies, and Job-Seeking Intensity in Unemployed Adults. J Appl Psychol 94(3), 806-13.

24. Kanfer R, Wanberg CR, Kantrowitz TM (2001) Job search and employment: A personality - Motivational analysis and meta-analytic review. J Appl Psychol $86(5), 837-55$. 
25. Skinner EA, Edge K, Altman J, Sherwood H (2003) Searching for the structure of coping: A review and critique of category systems for classifying ways of coping. Psychological Bulletin 129(2), 216-69.

26. Evans K (2007) Concepts of bounded agency in education, work, and the personal lives of young adults. International Journal of Psychology 42(2), 85-93.

27. Biesta G, Tedder M (2007) Agency and learning in the lifecourse: Towards an ecological perspective. Studies in the Education of Adults 39(2), 132-49.

28. Mishler EG (1999) Storylines: craftartists' narratives of identity, Harvard University Press, Cambridge.

29. Zikic J, Saks AM (2009) Job search and social cognitive theory: The role of career-relevant activities. Journal of Vocational Behavior 74(1), 117-27.

30. McDonald S, Elder GH (2006) When does social capital matter? Non-searching for jobs across the life course. Social Forces 85(1), 521-49.

31. Latack JC, Dozier JB (1986) After the ax falls: Job loss as a career transition. Academy of Management Review 11(2), 375-92.

32. Eby LT, Buch K (1995) Job loss as career growth: Responses to involuntary career transitions. Career Development Quarterly 4426-.

33. Ezzy D (2000) Fate and agency in job loss narratives. Qualitative sociology 23(1), 121-34.

34. Ezzy D (2001) Narrating unemployment, Ashgate, Aldershot.

35. Zikic J, Klehe UC (2006) Job loss as a blessing in disguise: the role of career exploration and career planning in predicting reemployment quality. Journal of Vocational Behavior 69(3), 391-409.

36. Beck U, Giddens A, Lash S (1994) Reflexive modernization: politics, tradition and aesthetics in the modern social order, Stanford Univ Pr, Stanford.

37. Giddens A (1991) Modernity and self-identity: self and society in the late modern age, Stanford Univ. Press, Stanford.

38. Edwards R, Ranson S, Strain M (2002) Reflexivity: towards a theory of lifelong learning. International journal of lifelong education 21(6), 525-36. 